Bulletin d'Histoire Contemporaine de

I'Espagne

$54 \mid 2020$

Les espaces du politique dans l'Espagne du Trienio liberal (1820-1823)

\title{
Interpretant el segle xx. Primera aproximació
}

Une interprétation $\mathrm{du} X X^{e}$ siècle. Première approche

A 20th century interpretation. First approach

Jordi Casassas

URL : http://journals.openedition.org/bhce/2868

DOI : $10.4000 /$ bhce.2868

ISSN : 1968-3723

Éditeur

Presses Universitaires de Provence

Édition imprimée

Date de publication : 1 janvier 2020

ISSN : 0987-4135

Référence électronique

Jordi Casassas, «Interpretant el segle xx. Primera aproximació », Bulletin d'Histoire Contemporaine de I'Espagne [En ligne], 54 | 2020, mis en ligne le 01 juillet 2020, consulté le 02 janvier 2021. URL : http:// journals.openedition.org/bhce/2868; DOI : https://doi.org/10.4000/bhce.2868

Ce document a été généré automatiquement le 2 janvier 2021.

Bulletin d'histoire contemporaine de l'Espagne 


\title{
Interpretant el segle xx. Primera aproximació
}

\author{
Une interprétation $\mathrm{du} X \mathrm{XX}^{e}$ siècle. Première approche \\ A 20th century interpretation. First approach
}

Jordi Casassas

Com exercici de reflexió que és el que ara us presento, i no una simple narració concatenada de fets, no us he volgut estalviar el recorregut lògic de la meva reflexió; així doncs, us trobareu que vaig anant endavant i enrere en el temps. Us volia avisar abans de començar tot excusar-me de la dificultat afegida que això representarà. He dividit aquesta reflexió en quatre apartats que he subtitulat: unes consideracions prèvies sobre les meves motivacions; la consciència del segle per la seva periodització; els principals eixos explicatius del segle XX; i unes consideracions complementàries $\mathrm{i}$ finals que he titulat « que les interpretacions no ens facin oblidar els fets » . Segle XX, mètode, filosofia de la història

1 Els historiadors, especialment els contemporaneïstes que tenim tant a prop el nostre objecte d'estudi, estem obligats a pensar de tant en tant en el que fem i en el cóm ho fem si no volem caure en la simple crònica o en l'anàlisi de petites coses que no interessen més enllà d'uns pocs especialistes. Per altra banda, com que els nostres temes es mouen amb el simple pas del temps, estem obligats a repensar periòdicament els límits si més no cronològics de la nostra matèria: podem seguir justificant hores d'ara l'origen del «món actual» en l'any 1945?

2 Com exercici de reflexió que és el que ara us presento, i no una simple narració concatenada de fets, no us he volgut estalviar el recorregut lògic de la meva reflexió; així doncs, us trobareu que vaig anant endavant i enrere en el temps. Us volia avisar abans de començar tot excusar-me de la dificultat afegida que això representarà.

3 He dividit aquesta reflexió en quatre apartats que he subtitulat: unes consideracions prèvies sobre les meves motivacions; la consciència del segle per la seva periodització; els principals eixos explicatius del segle XX; i unes consideracions complementàries $\mathrm{i}$ finals que he titulat «que les interpretacions no ens facin oblidar els fets». 


\section{Unes consideracions prèvies}

Com sabreu alguns, darrerament he publicat un llibre sobre el Noucentisme català. He hagut de pensar en les relacions entre la història local i la general; $i$ he hagut de diferenciar entre el noucentisme projecte i el noucentisme període, cosa que m'ha portat a reflexionar sobre què és el que caracteritza la dinàmica del segle XX. Abans d'aventurar-me a fer una explicació d'aquesta magnitud, voldria precisar algunes de les qüestions que han determinat la meva reflexió d'ara.

5 Tots hem repetit en més d'una ocasió allò de que la història la fan els vencedors. Doncs be, la història del segle XX ha estat tant dramàtica i ha produït tal quantitat de vençuts que no és estrany que es multipliquin els revisionismes. Així doncs, no podem convertir les nostres necessitats de revisió en un afer local sense córrer el risc de que el desconeixement de lo general per abandó converteixi les nostres anàlisis en quelcom incomprensible fora del nostre espai de referència.

6 En un altre ordre de coses i a base d'anys i ganes he hagut de fer un gran esforç per abandonar el conjunt d'apriorismes que tenen el seu origen en la ideologia i que a vegades els disfressem de mètode. El segle XX ens ha deixat com una de les seves pitjors herències el regne de les doctrines: la negació del pensament lliure, de la crítica, la inclinació a "pensar» en contra de l'altre (al qui considerem l'enemic). El segle XVIII va ser el segle dels filòsofs; el XIX el de les grans ideologies; i el XX el de les doctrines fetes aparentment com la continuació de les ideologies però que les neguen a base d'utilitzar «idees armades»; un dels grans doctrinaris del segle XX, Georg Lukács al seu llibre Història $i$ consciència de classe (1923) va poder afirmar que «si aquests són els fets, aleshores pitjor pels fets». Ha estat un pendent terrible que als historiadors ens ha pogut fer córrer el risc de caure en plantejaments progressivament simplistes o dualistes $\mathrm{i}$ que ha portat a molts a caure en la mania de judicialitzar el passat. Sortosament, la humanitat és molt més complexa que allò que ha sigut capaç de pensar.

7 Tots sabem el risc que correm els historiadors de caure en el presentisme. En el camp de la història contemporània és molt fàcil caure-hi. Sovint tractem temes encara no tancats i que ens afecten com a ciutadans, amb el que és molt difícil no prendre partit, ni que sigui inconscientment; el vocabulari i l'ús dels conceptes sovint es converteix en un vertader parany. Ara be, la lluita en contra dels presentismes no ens pot fer oblidar que qüestionem el passat des de les preocupacions del present i que cada present ha de preguntar-se coses del passat que segurament diferiran de les que s'interrogaven la gent d'una generació anterior.

8 Encara voldria destacar una altra prevenció. Es tracta de no caure en l'error de combinar arbitràriament la dinàmica dels fets amb la seva teorització, feta coetàniament $\mathrm{o}$ a posteriori, cosa que és pitjor. A vegades, aquesta substitució la fem inconscientment, per mirar d'omplir buits produïts per un dèficit de recerca. Com va dir el suís Jacob Burckhardt a finals del vuit-cents, en clara oposició a l'idealisme hegelià, les definicions conceptuals corresponen a la lògica però no a la història; en aquesta darrera, tot es presenta -deia- en «estat fluid», a base de combinacions continuades, i res s'hi dona d'una manera neta i precisa. 


\section{La consciència del segle per la seva periodització}

Sembla que a l'acostar-se a l'anàlisi de períodes amplis espacialment i cronològica el més prudent es començar per fer-ne la periodització. Així tenim la sensació de poder agrupar més fets (sense caure en la simple crònica) i donar-los un sentit. Per fer això crec que haurem d'evitar partir d'un judici de valor que, en l'anàlisi del segle XX, sovint no significa una forma d'ordenació sino més aviat una cacera de responsables. Penso que els fets rellevants capaços de fer de fita o partió cronològica haurien de ser aquells que han tingut especial força per a produir un canvi social, cultural i polític durable. En relació al temps històric voldria retreure encara una reflexió de J. L. Borges quan afirmava que un esdeveniment es produeix en un moment precís però que no l'acabem d'entendre ni de prendre'n consciència fins molt més endavant. Penso que és una forma aparentment simple però elegant de prevenir-nos sobre la relativitat no mecànica del temps històric i sobre els paranys que ens ofereix l'ús de la memòria.

10 La pròpia periodització ha de canviar per força amb el pas del temps i el canvi de preocupacions i sensibilitats amb les que ens encarem al passat. Les perioditzacions passades ens poden servir d'orientació però quan van estar fetes en marcs culturals allunyats del nostre haurem de ser molt prudents a l'hora de reproduir-les mecànicament: més aviat diria que es tracta de perioditzacions que elles mateixes es converteixen en objecte d'estudi doncs representen proves de la percepció que els seus autors tenien de la seva època a través de la manera com volien entendre el seu passat.

11 Sense cap voluntat d'exhaustivitat voldria centrar-me en un parell d'exemples de perioditzacions que en el seu moment varen ser determinants, que varen promoure rics debats historiogràfics i que podem considerar, d'aquesta manera, elements d'estudi de la seva època. Em refereixo a l'explicitada per G. Barraclough a la seva Guia de la història contemporània (1964) i a la popularitzada per E.H. Hobsbawm a L'edat dels extrems. El curt segle XX (1914-1991) (1994).

12 El professor anglès Geoffrey Barraclough (1908-1984) va evolucionar de medievalista a contemporaneista, va ser considerat el successor d'Arnold Toynbee i les seves obres varen gaudir d'un èxit notable. Una de les de major impacte fou precisament la Guia de 1964, obra que ell mateix declarà que havia concebut el 1956, segurament intentant entendre l'abast de fets com l'ascens de Jruschov al primer secretariat del PCUS marcant la fi de l'estalinisme, la declaració dels països no alineats impulsada per Tito, la crisi de Suez, la insurrecció antisoviètica de Budapest o la ocupació israeliana del Sinaí, tots ells fets que s'havien produït el 1956. Cal entendre que el naixement acadèmic de la disciplina contemporània tot just s'havia produït el 1918 (per relació a l'enorme impacte produït per la Gran Guerra) i la reflexió de Barraclough sobre el període contemporani devia ser de les primeres després del gran desastre de 1914-1945.

13 Més que una narració dels fets a aquest historiador li interessà entendre en què consistia la contemporaneïtat, a la qual va presentar com un procés de fronteres imprecises. Així i tot, la complexitat del tema el va portar a establir una periodització. Voldria destacar que ens trobem al davant d'un exemple fantàstic de l'historiador que es sent interpellat per la realitat que l'envolta, que reflexiona críticament i que fa la seva feina en conseqüència. Uns vuitanta anys abans, el ja mencionat J. Burckhardt havia fet una cosa semblant en relació al seu present i a la seva contemporaneïtat, que feia arrencar de la Revolució Francesa. 
Barraclough va afirmar que «la història contemporània comença quan els problemes que són actuals en el món actual assumeixen per primera vegada una fesomia clara»; i es va referir a uns processos iniciats al voltant de 1870: la dita segona revolució industrial, la revolució científica-tecnològica, la revolució demogràfica o l'esclat dels nous conflictes nacionals i socials sorgits en el sí de la nova societat de masses, tots ells processos en progressiva interacció. Com a bon representant dels vencedors dels horrors de la primera meitat del segle aquest historiador fou un optimista que mirava cap el futur, rebutjant els factors de continuïtat en història i pensant que aquesta està feta de salts fortuïts, de processos revolucionaris. L'altra gran fenomen que segons Barraclough separava la llarga època moderna de la contemporaneïtat era l'aparició d'un nou «sistema global de la política internacional», doncs segons ell els problemes determinats de forma hegemònica per Europa havien estat propis de l'època moderna. En conseqüència, i en la necessitat de posar una data a l'inici del període es decantava pel 1890, quan Bismarck era "acomiadat» de la cancelleria per l'emperador Guillem II, es deixava enrere la política de segle XIX i s'iniciava l'escalada imperialista que precipitaria la Gran Guerra. En el món contemporani es marxarà en direcció oposada de la del vell món del segle XIX fins a produir un canvi fonamental en les actituds de la gent.

15 Si volguéssim trobar algunes fonts d'inspiració de l'obra de Barraclough crec que podríem apuntar a J. M. Keynes (1883-1946), Les conseqüències econòmiques de la pau (1919) o a la gran obra de l'hongarès Karoly Polanyi (1886-1964), La gran transformació. Els orígens econòmics i polítics de la nostra època (1944), llibre que va ser força silenciat en la primera fase dura de la guerra freda doncs atacava tant l'evolució de l'economia liberal de mercat com l'economicisme comunista. Per la seva banda, Barraclough va voler posar una fita final a l'època contemporània. Es va decantar pel 1961 i els canvis de tendència que semblaven endevinar-se al món; i al simbolitzar-ho amb l'ascens a la presidència de J. F. Kennedy va voler veure-hi l'ascens a llocs de gran responsabilitat de gent que ja no estava determinada per la política anterior a 1939 i que va permetre superar, per exemple, la perillosa crisi dels míssils a Cuba de l'octubre de 1962. Segons ell, aquest nou món venia determinat per l'ascens de Brejnev a la presidència de la URSS, per l'inici de la carrera espacial, per l'esclat d'independències com a conseqüència del procés iniciat a Bandung, pel nou marc obert per les relacions Xinosoviètiques, per la suavització de la guerra freda, pel procés que portaria a la celebració del concili Vaticà II, per la consolidació inicial del procés regional europeu iniciat en el Tractat de Roma o pels primers passos de la revolució electrònica. El que no quedava clar, i per a Barraclough era difícil tenir la perspectiva suficient, era en què consistiria el període que s'obria amb aquesta arrencada dels seixanta.

16 Podem dir amb Barraclough que a tota una generació nascuda en els anys vuitanta i formats en valors molt de segle XIX els va semblar que el gran impacte de la ciència i la tècnica estava provocant una fissura insalvable en el flux històric així com dubtes seriosos de poder compassar la ciència amb la democràcia, com a mínim la que ells havien conegut fins aleshores. Normalment, fins i tot els crítics més aguts no encertaren en les seves prediccions sobre en què consistiria el nou segle. Tothom coincidia en que el segle XIX havia estat el segle britànic. Però a l'hora d'atribuir la nova hegemonia la cosa no era tan clara. Persistien els tics eurocentristes i fins i tot el prestigiós Daily Telegraph no dubtava que la potència mundial del futur seria Alemanya, pel seu potencial científic, per la seva capacitat d'organització, per l'orgull que sentia 
pel seu passat i la fe en el seu futur (en contrast amb els dubtes britànics quan començaven a descobrir la seva vulnerabilitat). Pocs van ser els que abans de la Gran Guerra vaticinaren l'hegemonia dels EEUU i els efectes trasbalsadors per a les formes de vida tradicionals de l'americanització d'Europa: potser l'historiador anglès John Seeley va ser un dels primers quan al seu aleshores renombrat llibre sobre L'expansió d'Anglaterra, del 1883, vaticinava el proper declivi d'Europa davant la força imparable de grans agregacions com els EE UU i Rússia. No oblidem que a finals del segle XIX la geografia es va convertir en geopolítica.

L'altra periodització que va provocar gran impacte i nombrosos debats acadèmics fou la del «segle curt» de Hobsbawm (1994), manllevant el terme de l'historiador hongarès Iván Berend. Per a l'historiador jueu, marxista, centreuropeu i naturalitzat anglès, per tant un perfecte cosmopolita, el determinant era el cicle marcat per l'ascens i la caiguda del projecte socialista marxista, inclosos els anys de l'estalinisme doncs fou aleshores quan el comunisme va esdevenir global en acomplir l'esforç titànic d'ajudar a les democràcies occidentals a derrotar al nazisme. M'estalvio una descripció detallada de les tesis de Hobsbawm doncs són prou conegudes i la seva periodització segueix essent utilitzada per molts historiadors. Les fites del segle XX les situava entre la Gran Guerra i el collapse comunista de 1989. Penso que s'ha de tenir molt present que Hobsbawm va escriure el seu llibre en una conjuntura determinada per l'enorme impacte mundial que va produir l'ensorrada del món de l'Est. En aquesta tessitura era lògic girar els ulls cap a l'origen del $1917 \mathrm{i}$ entendre aquests anys centrals del nou-cents com els determinats per la confrontació dual entre el comunisme i el capitalisme. De tota manera, cal tenir present que quan l'historiador naturalitzat anglès Donald Sassoon va publicar Cent anys de socialisme. L'esquerra a l'Europa occidental al segle XX (1997) no situava l'inici d'aquesta centúria socialista en l'any 1917 si no en el $1889 \mathrm{amb}$ la fundació de la IIa. Internacional.

Però, entrat el segle XXI podem seguir ancorats en aquesta cronologia "curta»? El segle $\mathrm{XX}$ va venir determinat centralment per aquest dualisme antagònic? De fet, la ruptura de 1989-1991 va fer emergir processos ètnics, geogràfics, religiosos, nacionals, identitaris o de memòria que semblaven superats del tot i que tenien el seu origen en el segle XIX, si no abans. Penso que això ens ha de fer pensar en si la revolució comunista va avançar realment i de forma irreversible en la seva promesa de destruir les velles classes socials, l'estat i la nació burgesos, el mercat o la religió. Així, penso que no podem parlar de forma unilateral de la crisi del món de l'Est com d'un procés autònom que per si sol havia donat sentit al segle XX mundial. Més aviat hauríem de pensar que la crisi del món de l'Est va formar part d'un procés molt més gran i d'abast general en el qual es va perdre la fe en poder seguir mantenint el control polític del canvi social: allò que Mark Mazower el 1998 denominava com el «contracte social en crisi», i en el que els països socialistes es demostraren incapaços de contrarestar-ho, així com de revertir el seu retardament econòmic o de resistir a l'avenç d'una cultura global determinada per la necessitat cada cop més generalitzada de respondre als desafiaments mediambientals, de la llibertat d'expressió, de la reivindicació de gènere o a la individualització de les identitats.

19 En definitiva penso que la periodització de Hobsbawm, sens dubte suggerent i tant ben explicada, responia en el fonamental, com ja he avançat, a les exigències d'una conjuntura política i cultural molt determinada per l'impacte de l'ensulsiada de 1989. En bona part, en situar l'inici del segle en la Gran Guerra coincidia en la cronologia 
avançada per Arno Mayer en el seu estudi sobre la pervivència de l'Antic Règim, publicada el 1981, encara que aquest darrer, seguint l'argumentació d'Alexis de Tocqueville, estava més preocupat per entendre el final del segle XIX que no pas per determinar la naturalesa del segle XX. Pel que fa al nou-cents Hobsbawm considerava que el drama d'aquest segle havia consistit en la concatenació de les dues guerres mundials interrelacionant amb un sistema econòmic en canvi constant, amb el resultat de deixar en herència el sistema internacional menys estructurat dels darrers dos-cents anys i que, per afegitó, s'havia d'enfrontar als perills de la degradació ecològica i de l'explosió demogràfica. La combinació d'aquest drama amb els elements d'esplendor (benestar, allargament de l'esperança de vida, comunicacions, extensió de l'ensenyament, etc.) li feia parlar de l'edat dels extrems.

Cal dir que el propi Hobsbawm (1917-2012) va fer una mena de revisió de la seva "edat dels extrems» al llibre titulat $\mathrm{La}$ fi de l'estat, publicat el 2000. En aquest treball abordava tres temes que considerava essencials per entendre per on havia evolucionat el món després de 1989, en l'època de la globalització extrema: parlava de l'evolució del nacionalisme, de la prospectiva de la democràcia liberal i de la qüestió de la violència política i del terrorisme. Hobsbawm hi desgranava tota una sèrie d'elements que segons ell caracteritzaven el post segle XX: el buidatge de competències del vell estat nacional refermant la crisi del sistema internacional de poder; l'entrada en el mercat de multitud d'armes de destrucció massiva i la proliferació de «guerres asimètriques» que reobrien les massacres, genocidis, neteges ètniques com mai s'havia vist des de $1945 \mathrm{i}$, amb ells, l'onada de refugiats, fugitius, desplaçats, etc.; altre factor que destacava era l'extraordinària acceleració de la globalització i el canvi en la composició de les societats nacionals, en la valoració del concepte de ciutadania així com en l'aparició d'actituds com la xenofòbia, que ara veia generalitzada. Aquest darrer tret, amb el corolllari d'hostilitats econòmiques, culturals, religioses, etc. havia posat en qüestió les velles cohesions nacionals i fet aparèixer unes reaccions violentes provocades per la por alhora que contribuït a reforçar el procés d'individualització de les societats occidentals.

21 Finalment, en els darrers anys de la seva vida Hobsbawm va anar preparant un text que es publicaria pòstumament el $2013 \mathrm{amb}$ el títol Fractured Times. Culture and Society in the 20th Century, en el que fins i tot hi trobem certs elements autobiogràfics. En ell va voler analitzar la fractura cultural i artística que es produïa en el sí d'una societat desorientada i que mirava endavant sense saber cap on anar. Així, Hobsbawm reconeixia una desorientació general en la societat de finals del segle XX i de principis del segle XXI, com si la fi del nou-cents hagués obert un període incert de transició encara per definir. La fi del segle ja no ho era la del cicle socialista si no la d'un model global de societat «desorientada». I pel que feia a aquest model es referia al cicle de la superioritat de la civilització burgesa europea que, malgrat el collapse a la que la va sotmetre la Gran Guerra, havia seguit mantenint el sentiment de superioritat científica, cultural i espiritual. I per tal de buscar l'origen d'aquest cicle burgés Hobsbawm es veia obligat a situar-se a finals del segle XIX.

22 Així doncs, per explicar-se aquesta crisi burgesa amb la que veia cloure's el segle XX Hobsbawm parlava d'elements com l'impacte de la ciència en la vella civilització del progrés vuitcentista, d'un modus de producció depredador i d'un sistema polític i institucional pensat per i per a unes elits meritocràtiques que no van poder assumir l'ascens de les masses, sobretot en els anys posteriors a 1945. Aquestes masses podrien 
haver optat per la via socialista (comunista, revolucionària) com la solució però, sempre segons aquest autor, el que feren fou optar per la via socialdemòcrata que els permetia accedir al model burgés sense grans traumes: ja veieu que hi ha historiadors que poden acomodar els fets a la seva ideologia, fins el punt de fer responsable a la gent de la no adeqüació. Per la seva banda, sempre segons Hobsbawm, les elits no varen poder resistir l'impacte de la revolució científica i tècnica, la consolidació de la societat de consum o l'ascens de les masses a un nou protagonisme polític electoral; així mateix destacava el xoc entre la globalització i el manteniment de la vigència de l'estat nació, o la contradicció que es produïa entre la desaparició de les normes en art al mateix temps en que aquest es veia determinat per les exigències del mercat (amb una importància creixent de la cultura de l'entreteniment). Aquesta darrera i pòstuma aportació de Hobsbawm crec que dona molta més profunditat a la seva visió del segle XX, tot contradient en bona mesura l'anterior del «segle curt».

En aquesta línia, personalment crec que a principis del segle XXI cal entendre el noucents com un segle llarg que comença en els anys setanta del vuit-cents i que simbòlicament acabarà el $1973 \mathrm{amb}$ la gran crisi energètica: el petroli també havia posat un inici al segle XX, com va remarcar Schumpeter amb la seva teoria del desenvolupament econòmic de 1912; així mateix, ull que també la crisi de 1873 havia estat la primera gran interrupció del creixement vuitcentista, amb aquesta coincidència enigmàtica de les dates de les crisis acabades en 73. A partir d'aquí s'iniciarà un període que encara ens veiem obligats a catalogar com de transició perquè és difícil determinar cap on va. Potser si que podem aillar uns quants elements d'aquest final incert del segle XX: entre altres, la internacionalització de les grans corporacions (multinacionals), la deslocalització industrial i l'extensió del fordisme a Àsia, el nou món de la riquesa en el marc de la globalització i el seu control transnacional de la informació, la crisi de l'estat nació tradicional i del seu vell sistema de partits, el collapse de l'humanisme marxista, o la consolidació de la visió postmoderna que abandona tota aspiració utòpica en favor de la sacralització fragmentària del present $\mathrm{i}$ de l'oblit metòdic del que havia estat lo modern.

Encara voldria afegir un darrer element que m'inclina a posar fi al segle XX en el 1973. En aquest any s'iniciaven a Hèlsinki les reunions de la Conferència de Seguretat $i$ Cooperació a Europa que van involucrar a trenta-dos països d'aquest continent, i a la URSS, els EEUU i Canadà. Les reunions s'acabaren el 1975 i comportaren acords fonamentals com la cerca de les solucions pacífiques dels conflictes, el respecte a la integritat territorial dels signants, el respecte a les llibertats fonamentals $i$ als drets humans o la cooperació entre estats. Per tant, havia estat el 1973 quan s'havia intentat posar fi a la guerra freda, i no el 1989, acceptant el món de l'est el respecte als drets individuals a canvi d'una cooperació imprescindible per a suportar les seves economies en fallida. Dit sigui de passada, el nou clima acordat a Finlàndia entre 1973 i $1975 \mathrm{crec}$ que també va intervenir, i de manera penso que força decisiva, en la caiguda de les dictadures en el Mediterrani.

Hi ha un parell més de grans esdeveniments que ens fan de frontera en aquests anys setanta. Per un cantó, la derrota de la superpotència americana al Viet-Nam; i, per l'altra, l'esclat a finals de la dècada de la revolució islàmica, que com recordava el propi Hobsbawm va ser la primera que no va fonamentar el seu ideari en la Il-lustració. 


\section{Principals eixos del segle $x x$} acabem de delimitar cronològicament i temàticament? Quins van ser els eixos fonamentals a la vista de l'evolució de l'actual període que hem catalogat com de transició que ens determina actualment? Quina consciència es va tenir, finalment, en cada un dels finals de segle -el del XIX i el del XX- de l'existència d'una sèrie de factors que diferenciaven una època de l'altra?

En el referent a les percepcions hi ha un element diferenciador que consisteix en què a l'inici del nou-cents existia una voluntat quasi militant de diferenciar-se del segle XIX, mentre que a principis del segle XXI la voluntat és la de no ser diferent del segle XX (de poder-ne recuperar el millor) però de fet ho és de diferent, sense voler-ho. Això, per exemple, ho veiem en el fet que la gent de principis del segle XX quan va voler superar el gran sotrac de les guerres mundials concatenades va posar en marxa a l'occident el wlfare state, preocupada pel benestar collectiu. Contràriament, la gent que es responsabilitzarà de l'arrencada del segle XXI el que haurà fet és desmantellar-lo $\mathrm{i}$ privilegiar el benestar individual davant el que defineixen com la bancarrota de lo collectiu. És clar que en un i altre període aquest posicionament ha afectat a una elit i això ens obliga a tenir molt present la distància creixent entre la cultura de les elits i la de les masses. A les darreries del segle XX, en el darrer quart que obre la transició on encara estem installats, aquestes elits estaran determinades en bona mesura per lo post, pel postmodernisme, el post-estructuralisme, la societat postindustrial o postnacional ( $\mathrm{i}$ per tendències com el minimalisme o la desregulació) que indirectament o per oposició assenyalen els grans temes que havien caracteritzat el segle XX i que declaren voler superar. I pel que fa a les masses, la universalització d'un ensenyament acrític i des-educador les deixa inermes davant qualsevol intent de manipulació, fins el punt que s'ha pogut afirmar que hem entrat en l'era de la postveritat.

Des de pràcticament el mateix inici del nou-cents occidental s'havia installat una significativa filosofia i una literatura de la fi, plena de nostàlgies del món que estava desapareixent $\mathrm{i}$ dels valors sobre els que s'havia fonamentat (aquí resulta obligat recordar l'obra pòstuma de Sefan Zweig, El món d'ahir. Memòries d'un europeu, 1942) o la que es referia a un sentiment pregon de malestar de la civilització, de presagis sobre la decadència d'occident (l'obra d'o. Spengler, per exemple). Hi haurà tota una sèrie de paraules que es començaran a repetir de forma simptomàtica: agonia, apocalipsi, suïcidi col-lectiu, catàstrofe (cultural, mediambiental, etc.), ceguesa o fracàs: el malestar de la cultura afectarà als camps més variats. Un exemple entre molts d'aquesta literatura del pessimisme amb el que els europeus s'enfrontaven a la irrupció del segle XX ens el dona l'historiador francès Daniel Halévy, amic de M. Proust, Ch. Péguy o G. Sorel. El 1903 va publicar una curiosa «novella d'anticipació» que titulà Història de quatre anys (1997-2001). En ella vaticinava la condemna del segle XX, per la seva deriva demagògica i la preponderància de la cultura de l'oci, el plaer i la mort. Halévy s'arrenglerava amb els crítics de la modernitat tot parlant pejorativament, per exemple, de la "democràcia de carrer».

Tot i la dificultat de reduir a enunciats curts uns processos realment tant complexos i plurals voldria proposar cinc o sis grans eixos que a parer meu han determinat i que ens ajuden a explicar què ha estat el segle XX: 1) la revolució industrial, científic- 
tècnica i urbana; 2) la consolidació de la nova societat de masses i de la democràcia de masses; 3) el desfermar-se de la violència moderna; 4) la consolidació del nou estat nacional total; i 5) el final de l'Europa-Món i els efectes de la globalització.

Hi hauria un sisè eix que es centraria en destacar el cicle socialista que centrava la periodització de Hobsbawm. Sens dubte s'ha tractat d'un element molt important en el desenvolupament dels fets que han marcat el segle XX. Però ni crec que va ser un factor determinant en l'arrencada del segle XX ni un element que es debatés centralment en l'obertura del període de transició que va cloure aquesta centúria. Que la revolució s'hagués produït a Rússia, potser el país més pobre d'Europa no ho preveia ni el socialisme científic del segle XIX, i la derrota de la revolució bolxevic a Alemanya va impedir l'extensió d'aquesta revolució a l'Europa desenvolupada. Després de la mort de Lenin, el gener de 1924, l'estratègia bàsica va consistir en salvar la revolució en un sol país i aquesta progressiva «normalització» internacional va portar a l'acceptació de la URSS en la Societat de Nacions l'any 1934. Posteriorment, amb el gran procés de descolonització podem parlar d'una simbiosi entre el comunisme i el nacionalisme com elements destacats que hi participaren.

31 En considerar aquesta mena de grans eixos l'historiador nordamericà Charles S. Maier (1939) opinava que ben be podrien fer-nos considerar un procés llarg de la contemporaneïtat que englobés els segles XIX i XX (va parlar de la unitat històrica de l'edat industrial), en el que el primer segle aportaria la constitució bàsica de la civilització burgesa i el segon la lluita d'aquesta amb el gran esforç per construir la nova economia i societat nacionals; en aquesta gran confrontació apareixeria la nova irracionalitat (Nietszche, Sorel, Freud, William James, Pareto, etc.) així com grans dosis de violència. Jo mateix vaig coordinar i collaborar a redactar un manual d'història mundial contemporània que vaig titular La construcción del presente. El mundo desde 1848 hasta nuestros días (2005). En ell s'assenyalava un inici d'època coincidint amb la irrupció en l'escena internacional (europea, aleshores) de la tendència a la unificació de l'estat nacional i l'inici del qüestionament de les velles estructures imperials de signe federal, de la reivindicació democràtica i del desafiament socialista així com de l'acceleració industrialista i dels transports.

Ara penso que a mitjans segle XIX si que s'havia produït l'arrencada d'una tendència, però que no va ser fins vint anys més tard, en la dècada dels setanta, quan la combinació de tots aquells factors produirien un canvi qualitatiu fenomenal i, amb ell, l'inici brutal de «l'edat dels extrems». El segle XX començà, com ja avançava, en aquest darrer quart del vuit-cents: quan la producció i la cultura material en general es varen veure sotmeses a la gran tensió produïda per la revolució científic- tècnica; quan aquesta, a més de precipitar el pas de la reflexió teòrica sobre la violència a fer-ne d'ella una realitat que envaïa totes les esferes de la vida, va influir en el canvi d'hàbits, en l'arrencada de l'explosió demogràfica contemporània, o en la concepció d'un món definitivament mundialitzat; i, encara que inicialment només en el camp de l'alta reflexió, determinat per la sospita que s'havia produït un vertader tall d'efectes irreversibles sobre el decurs històric. A partir d'aquest moment l'alta cultura va deixar de confiar en les seguretats de la «religió» positivista i es va refugiar en el vitalisme, en la força vital, en el relativisme o en dimensions desconegudes com la del somni froidià.

Com a conseqüència de tot plegat i potser com l'element fonamental que caracteritzaria el nou-cents, es va fer imprescindible una nova organització social, política i institucional basada en l'estat nacional total: que era el que passava a centralitzar 
l'acció de govern amb una funcionarització sense precedents, a controlar el conjunt dels seus habitants i a exercir el poder sobre els individus, els grups i el conjunt de les seves activitats privades o públiques; un estat que es convertia en l'agent principal de la nacionalització de la massa dels seus habitants i de la regulació d'una nova societat de masses que deixava de ser un afer relatiu només al proletariat per passar a afectar la pràctica totalitat de la societat mentre deteriorava fins a difuminar-la l'anterior societat de classes. Sense una classe mitjana ascendent, els emprenedors o els científics de tot tipus aquest nou estat nacional total no hauria ni tant sols pogut posar-se en marxa. En aquest procés la intellectualitat va iniciar el procés de la seva «traïció» (segons concepte de Julien Benda) tot convertint-se, sobretot a partir de la Gran Guerra, en clars agents de propaganda i manipulació de les masses. Els canvis i els seus efectes foren tant ràpids que alguns han afirmat que més que curt el segle XX anava a ser el segle veloç (Lenin no havia dubtat a definir el nou-cents que començava per la tendència a la mundialització i per la precipitació del temps històric).

Tots aquests factors afectaven fonamentalment el Vell Continent. Alguns crítics varen opinar que el segle XIX europeu havia produït molta més història que la que la seva gent podia digerir. Inicialment es tractà d'un problema de magnituds i es va poder parlar d'una simple crisi de creixement. Però aquests canvis es traduïren en enormes desplaçaments de la població i en el creixement desorbitat i suburbial de les ciutats, un niu de desequilibris, tensions i violència realment inèdit. Sense l'existència del que hem denominat l'estat nacionalitzador i total hagués estat materialment impossible el control d'aquests canvis.

Però ni així va ser possible que Europa recuperés el control del seu propi procés històric. Ningú va poder aturar la convicció creixent de que la violència era ja la única llevadora que podia infantar una nova recuperació de la història: aquí no podem oblidar bona part de l'obra, per altra part magnífica, d'Ernest Jünger; però, tant mateix, seria injust oblidar que gent de la talla de Thomas Mann o Max Weber s'alinearen amb el «partit de la guerra» alemany el 1914 (encara que poc després saberen rectificar); i sense oblidar tampoc que Marc Bloch el 1915 opinava que «els exèrcits nacionals han fet de la guerra un ferment democràtic», tant l'havia impactat l'entusiasme nacionalista de la primera mobilització militar. Tothom es va habituar a viure amb por, amb recel, amb una agressivitat creixent, en la inseguretat, en l'abús del poder o en la tendència creixent a portar els conflictes fins a l'extrem. Malgrat es parlés amb frivolitat d'una «belle époque» la realitat transitava pel pendent de la crisi, molt lluny dels valors culturals constitutius de l'era industrial europea. En una conferència pronunciada a Munic a finals del 1918 i que es va publicar amb el títol de «La ciència com a professió», Max Weber afirmava que Europa estava en runes i que tota la seva superioritat cultural s'havia demostrat impotent davant de la follia política.

La primera manifestació clara i global d'aquests problemes la denominem la crisi imperialista. Si les tensions europees eren l'element fonamental d'aquest nou panorama el medi en el que es precipitaren aquestes tensions configurarien l'ordre internacional futur. Alguna gent, per exemple l'agut Paul Valèry, es va adonar de que una crisi on ja comptés l'expansionisme japonès, la nova presència internacional dels EEUU o la ràpida descomposició dels imperis rus, otomà o austrohongarès (una crisi que es materialitzava a les Antilles o en el Sud-est asiàtic, molt lluny d'Europa) comportava canvis de fons que aleshores encara no es podien avaluar convenientment però que acabarien per inquietar la consciència europea. Aquesta crisi imperialista va 
precipitar la confluència explosiva de dos factors, el nacionalisme dels estats i l'armamentisme. Es tractà d'una confluència molt ràpida. Un exemple d'aquesta rapidesa ens el donà Fredrich Engels quan en la primera edició de Antidüring (1878) opinava que el militarisme estava abocat a la ruïna pels costos desorbitats de l'armament modern (es fixava especialment en el dels grans destructors); tant sols deu anys més tard, però, l'armamentisme ja era un fet tant evident que ell mateix alertava sobre el perill de la reunió entre el xovinisme i la guerra i assegurava que l'enfrontament entre exèrcits de milions d'homes devastaria Europa. La literatura també va recollir aquest perill destructor. No oblidem que molts historiadors es referiran a aquests anys com els de la "pau armada» Així, H. G. Wells el 1898 va publicar La guerra dels mons, pionera del gènere «d'anticipació científica», en la qual en el fons estava plantejant el tema de la perillositat de les innovacions tecnològiques tant destructives, però avisava també del perill de quedar-se enrere en aquesta cursa. L'armamentisme i el nacionalisme excloent es convertirien en uns altres dels trets definitoris del segle XX: alguns, no és el meu cas, han afirmat que el nacionalisme deixaria de ser determinant després de 1945 per reaparèixer en la dècada dels setanta.

\section{Que les grans interpretacions no ens facin negar els fets}

Fins aquí els límits cronològics del segle, que situàvem entre 1870 i 1973. El que ens correspon ara es avançar perioditzant l'interior d'aquesta centúria.

Hi ha historiadors que fins i tot han situat l'inici del segle XX al voltant del 1900. Donen importància a fets com la convocatòria de la primera conferència de La Haia el 1899 per crear una institució que previngués del risc de la guerra i impulsés el desarmament (però tres mesos desprès de cloure's la conferència esclatava la guerra dels boers); també destaquen la mort, el 24 de gener de 1901, de l' emperadriu anglesa Victòria, tot un símbol del vuit-cents; o la primera edició dels Premis Nobel el mateix 1901 en la que es donà el de la Pau al fundador de la Creu Roja, Henri Dunant; o a l'establiment el 1902 a La Haia del tribunal internacional per arbitrar entre països (no oblidem que molts historiadors espanyols el fan començar el segle en la crisi colonial de 1898). Es pot dir que cap d'aquests elements determinaran el segle XX, però no per això els podem oblidar sense córrer el risc de buidar de contingut el discurs històric. Alguns, prenent la part pel tot han arribat a parlar d'un segle XX determinat per la vigència de la senyal SOS de l'alfabet Morse: concretament des que la llençava el Titànic el 14 d'abril de 1912 i tot el món coneixia la tragèdia gracies a la recent unificació horària, fins al seu abandó oficial l'any 1997

Si ens mantenim en la reflexió general, però, crec que hem de tornar a fixar-nos en la visió donada per Hobsbawm en el seu «segle curt» per veure com la determinació del període 1917-1989 l'hi condicionava la periodització interior. En ella, aquest historiador diferenciava una època de la catàstrofe, d'una edat d'or i d'una edat final de la crisi. I el primer que podem constatar és que en les dues primeres «edats» mundials el comunisme no hi va jugar un paper determinant. Entès l'inici de la catàstrofe com el de la Gran Guerra veiem que el comunisme en fou una conseqüència, però no una causa determinant. I pel que fa a l'edat d'or, que Hobsbawm situa entre 1947 i 1973 i en el món occidental en base al seu excepcional progrés econòmic, social i civil, ens diu que aquest progrés es va donar en bona mesura gràcies a la confrontació exercida pel 
comunisme, amb el que pot reivindicar un cop més la seva caracterització «curta» i socialista del nou-cents.

40 Seguint, però, la periodització que jo he proposat més amunt m'atreveixo a partir el flux tens, complex i sovint contradictori del segle XX en tres subperíodes: de 1870 a 1913, els anys de la tensió de la modernitat; de 1914 a 1945, els de la guerra dels trenta anys del segle XX i de la barbàrie totalitària (fins el 1953 amb la mort de Stalin per al món de l'Est); i de 1945 a 1973, els anys de la tensió globalitzadora i de la guerra freda. Com és lògic no ens correspon ni podem narrar ara i aquí aquest segle XX amb un mínim detall. Tant sols vull destacar alguns aspectes que no han quedat inclosos en l'intent d'explicació general precedent.

41 Del primer subperíode voldria destacar un cop més la importància de la Gran Guerra. D'ella normalment en cerquem les causes, com hem fet també aquí, com una espècie de fatalitat a la que portava l'eclosió de la modernitat europea i el seu xoc violent amb la societat tradicional i dels vells problemes europeus. Molt poca gent en va preveure el seu caràcter terriblement nou, total, i cap dels seus protagonistes les seves conseqüències. Uns pocs si que van avisar dels perills d'una guerra que ja no seria com les conegudes fins aleshores. Nietzsche, per exemple, l'havia profetitzada; però qui ho feu més explícit va ser el vell general prussià i fidel amic de Bismarck Helmuth von Moltke quan el 1890 es va acomiadar del Reichstag: cap guerra ja seria igual, va dir, doncs seria de pobles contra pobles amb estats armats com mai i que només acabarien amb la total destrucció de l'enemic; i acabava maleint al qui s'atrevís a desencadenar una guerra així.

Es van cometre molts "oblits" fins que es desfermà aquesta pandèmia de la modernitat. Ja hem alludit al pendent pel que la violència s'ensenyorí dels comportaments $i$ actituds collectives dels europeus a partir de les atrocitats comeses en la darrera fase de la colonització (recordem la terrible denúncia feta per Joseph Conrad a $\mathrm{El}$ cor de les tenebres, de 1899). Davant de tot s'hi collocaren els estats totals que actuaren amb una inconsciència també total oblidant el mínim de prudència que fins aleshores havia presidit les relacions internacionals definides per darrera vegada en el Congrés de Viena de 1814-5. El fracàs de la segona Conferència de Berlin (1885) havia estat el primer avís del perill d'aquests desequilibris i, com ja hem comentat, la crisi imperialista oberta el 1895 en va ser el segon i darrer abans no es desfermés la guerra total de 1914-8. S'acabava d'aquesta manera una tendència de llarg recorregut que buscava consolidar l'equilibri internacional respectant el balance of power continental: s'havia iniciat amb la pau de Westfalia el 1648 i William Penn l'havia teoritzat en el seu Assaig sobre la pau present i futura d'Europa (1693); es va posar en pràctica a la pau d'Utrecht (1713) i l'abat Saint-Pierre ho explicà en la seva Memòria per donar la pau perpètua a Europa, del mateix 1713; posteriorment I. Kant ho elevà a la gran reflexió filosòfica-pràctica en el seu llibre Sobre la pau perpètua (1795), quan aquest equilibri estava altre cop en perill. En canvi ara els europeus es llençaren els uns en contra dels altres amb una rancúnia indescriptible, donant fe de que la nacionalització agressiva de les masses per part dels estats havia estat un èxit i en mig d'una majúscula inconsciència de fins quin punt disposaven de la capacitat d'autodestrucció continental sense el palliatiu d'una disciplina social o d'una maduresa cultural-educativa per poder-ne suportar les conseqüències.

43 Hi ha un altre factor que voldria destacar i que corre en parallel al de la nacionalització de les masses: es tracta del procés d'extensió i consolidació de la democràcia electoral 
com a democràcia de masses. Ambdós processos van tenir una cronologia similar i els hem d'entendre totalment lligats a la complexa problemàtica que envoltà el caòtic creixement de les ciutats fruit de la gran migració camp ciutat, dels canvis d'hàbits als que es va forçar a milions de persones, a la imposició de nous règims laborals, alimentaris, familiars, etc. El gran desconcert (l'anòmia durckheiniana) que això va provocar, els estats l'intentaren encarrilar amb la creació d'una nova moral collectiva que apellava a l'instint més que a la racionalitat (el nou nacionalisme) i amb la introducció d'un sufragi universal masculí amb el que es volia integrar les masses donant-los una aparença de responsabilitat pública nova, però que la corrupció electoral i parlamentària es van cuidar ben be de diluir en mig d'un ambient de violència creixent. Ningú es va cuidar, en canvi, de donar contingut real a tot això, com tampoc de donar eines per a que aquestes masses poguessin exercir les seves noves responsabilitats "democràtiques» de manera efectiva. Tant sols els grans sindicats de masses varen voler aprofitar les noves possibilitats, però abocant a la gent a una nova forma de passivitat moderna denunciada tant pels sectors revolucionaris (comunistes) com per la moderna sociologia de les elits (molt especialment Robert Michels). Penso que aquests dos factors de modernització crítica serien dos dels grans eixos del segle $\mathrm{XX}$ i ajuden a entendre per què s'hi va produir una polèmica constant (que durant uns anys va intervenir centralment en la confrontació de la guerra freda) sobre si existia realment un regim democràtic o si aquest es trobava en crisi permanent o passava etapes de consolidació seguides de períodes crítics. Sens dubte, la gran confrontació entre els totalitarismes i la democràcia va contribuir a sublimar aquest sistema polític de masses i a perdre la memòria dels seus precaris orígens.

De fet, Europa no pairà la seva "guerra europea» fins ben entrada la dècada dels seixanta. En part, això es va deure a què s'havia entès com una guerra civil entre europeus i, per tant, tothom en tenia part de la responsabilitat. La resta del món va haver de pair la realitat i els efectes acumulats de la segona Guerra Mundial, amb els seus horrors, amb la por de saber-se en condicions d'acabar amb la vida sobre la Terra, amb la pervivència d'uns ressentiments que la guerra freda mantindrà vius fins molt endavant, així com amb l'amenaça de que una nova recessió no tornés a fer possible la reaparició de nous visionaris amb les seves «fórmules» per a un mon nou. Però aquesta segona guerra es podia presentar de forma molt diversa de la primera: hi havia uns perdedors totalitaris que n'eren els responsables i l'havien perduda, amb el que els bons guanyadors podien respirar alleujats i passar pàgina.

Però, fos com fos, al capdavall el que comptava era, com havia dit Paul Valéry el 1919, que "nosaltres, els civilitzats, ara sabem que som mortals". I com diria Hanaah Arendt (i després va elaborar Habermas i la seva escola) davant aquell extermini en massa la història només podia fer que narrar-ho, impotent per analitzar-ho i menys encara per a explicar-ho. Però, i amb això vaig acabant, aquella violència organitzada i institucionalitzada fruit de la modernitat, en part es podia veure contrarestada per l'aparició dels moviments d'alliberament, pel corrent d'emancipació de la dona, pel corrent d'enriquiment de la democràcia, per l'augment de la seguretat i el benestar (en la darrera part del segle només es produiria un milió de morts enfront dels més de 150 del període 1914-1945), pels beneficis d'una imparable revolució científica, etc. És clar que l'evolució del que quedava de segle XX i l'obertura del posterior i tens període que hem denominat de transició es cuidaria de rebaixar força totes aquestes expectatives. El sociòleg i antropòleg francès Edgard Morin ho resumia dient que "el segle XX deixa una herència de mort $i$ alguns gèrmens d'esperança». Aquest autor, el 2005 va publicar 
un petit llibre, que va titular Culture et barbàrie européennes, on entre altres coses destacava la paradoxa d'una Europa occidental que ha estat el fogar de la dominació bàrbara del món alhora que de les idees humanistes i d'emancipació.

Malgrat tot el que porto dit fins aquí, centrat en les grans interpretacions, que com sempre es fan un cop els fets ja han succeït, haig de reivindicar per acabar el paper de la sort i la mala sort, de l'imprevist o del fortuït en història, per no caure sempre en mecanicismes «explicatius» tot fent equilibris malabars de tipus metodològic per explicar el que és difícil d'explicar: per exemple, per què el tzar de totes les Rússies, Nicolau II va abdicar sense soroll ni cap resistència en l'estació ferroviària de Pskov, un llogarret de mala mort a tres-cents kilòmetres al sud de Petrograd, a les $10 \mathrm{~h}$. del matí del 2 de març de 1917 ? Tal com va afirmar George Steiner a Una certa idea d'Europa, del 2004, fins i tot les idees més abstractes s'han d'ancorar en la realitat. Totalment d'acord.

UB. 5 d'octubre de 2018.

\section{RÉSUMÉS}

Je présente ici une réflexion et non une narration articulée de faits. Je n'ai pas voulu non plus vous soumettre à la logique celle-ci, c'est pourquoi je voyagerai parfois dans le temps. Cela représente une difficulté dont je suis conscient et pour laquelle je demande pardon par avance. Cette réflexion est divisée en quatre parties intitulées: considérations préliminaires, mes intentions, la compréhension du siècle par la périodisation, les principales explications du $\mathrm{XX}^{\mathrm{e}}$ siècle; et d'autres considérations que j'ai intitulées « que les interprétations ne nous fassent pas oublier les faits ".

I am presenting here a reflection and not an articulated narrative of facts. I didn't want to subject you to logic either, which is why I will sometimes travel in time. This is a difficulty that I am aware of and for which I apologize in advance. This reflection is divided into four parts entitled: preliminary considerations, about my intentions, understanding of the century by the periodication, the main explanations of the twentieth century; and other considerations that I have titled « interpretations do not make us forget the facts «.

\section{INDEX}

Mots-clés : XXe siècle, méthode, philosophie de l'Histoire.

Keywords : XXth century, method, History's philosophy

\section{AUTEUR}

JORDI CASASSAS

Universitat de Barcelona 